\title{
Habituation of plasma catecholamine responses to chronic intermittent restraint stress
}

\author{
MARIA KONARSKA, ROBERT E. STEWART, and RICHARD MCCARTY \\ University of Virginia, Charlottesville, Virginia
}

\begin{abstract}
Adult male Sprague-Dawley rats were exposed to restraint stress (RS) for 30 min per day for $0,5,12$, or 26 consecutive days. Each animal was then surgically prepared with an indwelling tail-artery catheter to permit direct measurements of mean arterial pressure (MAP, in $\mathrm{mm} \mathrm{Hg}$ ) and heart rate (HR, in beats per minute) on the day after surgery, and remote collection of blood samples during RS 2 days after surgery. Blood samples were later analyzed for plasma levels of norepinephrine and epinephrine to provide an assessment of the activity of the sympathetic-adrenal medullary system. Body-weight gain was reduced significantly in rats stressed for 12 or 26 days relative to handled controls. Baseline values of $\mathrm{HR}$ and of plasma levels of norepinephrine and epinephrine were similar in animals of the four groups. Baseline MAPs were lower in control rats and in those stressed for 26 days than in rats stressed for the previous 5 or 12 days. Plasma catecholamine responses to RS were reduced significantly in animals during the 6 th, 13th, or 27 th stress session relative to subjects restrained for the first time. These findings indicate that sympathetic-adrenal medullary responses are dampened rapidly when laboratory rats are exposed to chronic intermittent RS. In addition, the results of this experiment are consistent with our suggestion that habituation of sympathetic-adrenal medullary responsiveness occurs in animals exposed to chronic intermittent stress.
\end{abstract}

Kvetnansky and his coworkers have, over the past 20 years, examined the dynamic changes in the sympathetic-adrenal medullary system of laboratory rats exposed to chronic intermittent immobilization stress (Kvetnansky, Nemeth, Vigas, Oprsalova, \& Jurcovicova, 1984). The stress paradigm they have developed involves immobilizing laboratory rats for several hours per day for up to 40 consecutive days. Their studies to date indicate that a significant induction of adrenal medullary tyrosine hydroxylase occurs immediately after a single, 150-min bout of immobilization. Increases in activities of adrenal medullary dopamine-beta-hydroxylase and phenylethanolamine-N-methyl transferase occur within $6 \mathrm{~h}$ after a single bout of immobilization (Kvetnansky, Gerwitz, Weise, \& Kopin, 1971; Kvetnansky, Weise, \& Kopin, 1970). Elevations in activities of these catecholamine biosynthetic enzymes are maintained in animals exposed to immobilization stress each day for up to 1 year. Stressinduced elevations in tyrosine hydroxylase activity occur somewhat later in other sympathetically innervated tissues, including the heart (Kvetnansky, 1973, 1980). Thus, animals exposed to chronic intermittent stress have dramatic increases in catecholamine biosynthetic and storage capacities of peripheral tissues.

The research was supported in part by U.S. Public Health Service Grant MH39970 and by ADAMHA Research Scientist Development Award MH00529. We thank Susan Swithers, Debbie Mundie, and Andrew $\mathbf{H}$. Borom for their assistance, and Peter C. Brunjes for the use of his digitizing tablet. We also thank Eric A. Stone for his contributions to the design of this study. Address correspondence to Richard McCarty, Department of Psychology, University of Virginia, 102 Gilmer Hall, Charlottesville, VA 22903-2477.
Recent studies have shown that sympathetic-adrenal medullary responses of animals exposed repeatedly to the same stressor are actually reduced relative to responses of animals exposed to the same stressor for the first time (Konarska, Stewart, \& McCarty, 1989a; Kvetnansky et al., 1984). In these studies, plasma levels of norepinephrine and epinephrine were measured to provide an assessment of the activity of the sympathetic-adrenal medullary system (Goldstein, McCarty, Polinsky, \& Kopin, 1983; Kopin, Eisenhofer, \& Goldstein, 1988). We have suggested that habituation of sympathetic responses in chronically stressed animals would allow for conservation of energy by dampening physiological responses to a familiar and highly predictable event (McCarty, Horwatt, \& Konarska, 1988; McCarty \& Stone, 1984).

In the present study, we examined the time course for habituation of sympathetic-adrenal medullary responses to chronic intermittent stress. Using animals exposed to restraint stress for the first time as a baseline, we examined plasma levels of norepinephrine and epinephrine in laboratory rats during exposure to their 6 th, 13 th, or 27 th bout of restraint stress.

\section{METHOD}

\section{Animals}

Adult male Sprague-Dawley rats, weighing 275-300 g, were purchased from Dominion Laboratories, Dublin, VA. Upon arrival in our vivarium, the rats were housed individually in Wahmann suspended metal cages for at least 1 week prior to use. The vivarium room was maintained on a 12-h light-dark cycle (lights on $0700-$ $1900 \mathrm{~h}$ ) at an ambient temperature of $22^{\circ} \pm 1^{\circ} \mathrm{C}$. At all times, Purina Lab Chow and tap water were available ad lib. All experimental 
procedures described below were approved in advance by the Animal Care and Use Committee of the University of Virginia.

\section{Stress Protocol}

The animals were assigned at random to one of four groups, with 10 animals in each group at the beginning of the experiment. During the course of the 28-day experiment, the rats of the four groups were exposed to restraint stress (RS) in the following manner: Group RS-1, restraint stress on Day 28 only; Group RS-2, restraint stress on Days 22-26 and on Day 28; Group RS-3, restraint stress on Days 15-26 and on Day 28; and Group RS-4, restraint stress on Days 1-26 and on Day 28.

RS was accomplished by placing the rats into individual Plexiglas tubes $(6 \mathrm{~cm}$ diam $\times 22 \mathrm{~cm}$ long; IITC, Woodland Hills, CA) for $30 \mathrm{~min}$ per day between 1000 and $1500 \mathrm{~h}$. Body weights of the rats were measured each morning on Days 1-26 (refer to Table 1). The experiment was run in two waves of 20 rats, with 5 rats from each of the four groups included in each wave.

\section{Surgery}

On Day 26, the rats of the four groups were surgically prepared with chronic tail-artery catheters according to the method of Chiueh and Kopin (1978). At least $1 \mathrm{~h}$ after RS or weighing, the rats were anesthetized with sodium brevital $(60 \mathrm{mg} / \mathrm{kg}$, i.p.) and a $2-\mathrm{cm}$ incision was made through the ventral tail sheath near the base of the tail. The ventral tail artery was dissected free and elevated, and a 70-cm length of PE50 tubing was inserted into the artery at least $1 \mathrm{~cm}$ and secured into place with two 00 sutures. The tubing was led under the tail sheath and skin to exit in the midscapular region and was covered with a stainless steel extension spring (Dieco Co., Macedonia, $\mathrm{OH})$. The spring wire was fixed to the rat with an

Table 1

Summary of the Restraint Stress (RS) Protocol

\begin{tabular}{|c|c|c|c|c|}
\hline Test Day & Group 1 & Group 2 & Group 3 & Group 4 \\
\hline 1 & - & - & - & RS \\
\hline 2 & - & - & - & RS \\
\hline 3 & - & - & - & RS \\
\hline 4 & - & - & - & RS \\
\hline 5 & - & - & - & RS \\
\hline 6 & - & - & - & RS \\
\hline 7 & - & - & - & RS \\
\hline 8 & - & - & - & RS \\
\hline 9 & - & - & - & RS \\
\hline 10 & - & - & - & RS \\
\hline 11 & - & - & - & RS \\
\hline 12 & - & - & - & RS \\
\hline 13 & - & - & - & RS \\
\hline 14 & - & - & - & RS \\
\hline 15 & - & - & RS & RS \\
\hline 16 & - & - & RS & RS \\
\hline 17 & - & - & RS & RS \\
\hline 18 & - & - & RS & RS \\
\hline 19 & - & - & RS & RS \\
\hline 20 & - & - & RS & RS \\
\hline 21 & - & - & RS & RS \\
\hline 22 & - & RS & RS & RS \\
\hline 23 & - & RS & RS & RS \\
\hline 24 & - & RS & RS & RS \\
\hline 25 & - & RS & RS & RS \\
\hline 26 & - & RS & RS & RS \\
\hline
\end{tabular}

Surgical placement of tail-artery catheter

27 Direct measures of mean blood pressure and heart rate

28 RS $\quad$ RS $\quad$ RS $\quad$ RS

Note-Dashes denote days when the animals were handled and weighed only. RS was for 30 min per day as indicated. adhesive-tape collar. The tubing was filled with heparinized saline $(300$ I.U. $/ \mathrm{ml})$ and the end of the tubing was occluded with a 23gauge needle and a tuberculin syringe.

The rats recovered from surgery while under a heat lamp (surface temperature $28^{\circ} \mathrm{C}$ ). When fully awake (usually within $45 \mathrm{~min}$ ), the rats were placed individually into clear plastic cages $(35 \times 35$ $\times 22 \mathrm{~cm}$ ), which contained a layer of bedding material and Purina Lab Chow and tap water. The spring wire and catheter assembly were led out the top-center of the cage and secured so that each rat had complete freedom of movement about the cage. Catheters were flushed in the early morning and late afternoon with $0.5 \mathrm{ml}$ of heparinized saline to maintain patency of catheters.

\section{Sampling Procedure}

Between 0900 and $1100 \mathrm{~h}$ on the day after surgery (Day 27), resting values of mean arterial pressure (MAP, in $\mathrm{mm} \mathrm{Hg}$ ) and heart rate (HR, in beats per minute) were obtained while the rats were resting and undisturbed in their home cages. The end of the catheter was attached to a Statham pressure transducer with tracings made on a Grass multichannel polygraph. HR was recorded from a cardiotachometer triggered by arterial pulsations.

Two days after surgery (Day 28$)$, basal blood samples $(0.5 \mathrm{ml})$ were collected from each animal between 0900 and $1100 \mathrm{~h}$. Care was taken during the sampling process to avoid disturbing the animals. After each blood sample was collected, an equal volume of heparinized saline $(100 \mathrm{I} . \mathrm{U} . / \mathrm{ml})$ was infused slowly back into the catheter to maintain total blood volume. All rats were then exposed to RS for $30 \mathrm{~min}$ between 1100 and $1500 \mathrm{~h}$. Additional blood samples $(0.5 \mathrm{ml})$ were collected at 5,15 , and $30 \mathrm{~min}$ of the period of RS, and 5 and 15 min following RS, when the animals were back in their home cages.

\section{Assay of Plasma Catecholamines}

Blood samples were collected into iced, $10 \times 75 \mathrm{~mm}$ glass culture tubes and kept in an ice-water bath. Samples were centrifuged at $4,000 \mathrm{~g}$ for $10 \mathrm{~min}$ at $4^{\circ} \mathrm{C}$. Aliquots of cell-free plasma were removed and stored at $-70^{\circ} \mathrm{C}$ until assayed for content of norepinephrine and epinephrine by a radioenzymatic thin-layer chromatographic procedure (DaPrada \& Zurcher, 1976; Peuler \& Johnson, 1977). The sensitivity of the assay (values equal to twice blank) were less than $5 \mathrm{pg}$ for each amine, and all samples were assayed within 3 weeks after collection.

\section{Data Reduction and Analysis}

The results are presented as means $\pm S E M$ for the indicated numbers of animals. Comparisons among groups were made using oneway ANOVAs with post hoc Tukey-Kramer tests (Kirk, 1982). Results for plasma catecholamines were analyzed by computing an area under the curve (AUC, pg $\times$ min) for each animal. Briefly, the plasma norepinephrine and plasma epinephrine responses above baseline for each animal were plotted on graph paper and the AUCs were measured using a Hipad digitizing tablet (Bausch and Lomb, Austin, TX) interfaced with an IBM microcomputer using Sigmascan software (1985 version by Jandel Scientific, Sausalito, CA). The AUC provides a measure of each animal's catecholamine response profile during and following exposure to stressful stimulation (Konarska, Stewart, \& McCarty, 1989a, 1989b).

\section{RESULTS}

Body weights of the rats in the four treatment groups were quite similar on Day 1 , ranging from $323 \pm 6 \mathrm{~g}$ to $328 \pm 6 \mathrm{~g}$. At the time of surgery on Day 26 , however, body weights of the rats in Groups RS-3 and RS-4 were reduced relative to those of the rats in RS-1 and RS-2 groups. Body-weight gain differed across groups $[F(3,36)$ 
Table 2

Body-Weight Gain (in grams) from Days 1-26 for Rats in the Four Restraint Stress (RS) Groups

\begin{tabular}{|c|c|c|c|c|c|c|}
\hline \multirow{2}{*}{$\begin{array}{c}\text { Treatment } \\
\text { Group }\end{array}$} & \multicolumn{2}{|c|}{$\begin{array}{c}\text { Body Weight } \\
\text { Day } 1\end{array}$} & \multicolumn{2}{|c|}{$\begin{array}{c}\text { Body Weight } \\
\text { Day } 26\end{array}$} & \multicolumn{2}{|c|}{$\begin{array}{c}\text { Weight Gain } \\
\text { Day } 26 \text { - Day }\end{array}$} \\
\hline & $M$ & SEM & $M$ & $S E M$ & $M$ & $S E M$ \\
\hline RS-1 & 328 & 6 & 410 & 8 & 82 & 5 \\
\hline RS-2 & 327 & 8 & 407 & 9 & 80 & 8 \\
\hline RS-3 & 326 & 7 & 386 & 9 & 60 & 7 \\
\hline RS-4 & 323 & 6 & 385 & 5 & 62 & 3 \\
\hline
\end{tabular}

Note-Values are for groups of 10 rats.

Table 3

Baseline Values of Mean Arterial Pressure (MAP, in mm HG) and Heart Rate (HR, in beats per minute) on Experimental Day 27 for Rats in the Four Restraint Stress (RS) Groups

\begin{tabular}{crcccc}
\hline Treatment & \multicolumn{2}{c}{ MAP } & \multicolumn{2}{c}{ HR } \\
\cline { 2 - 3 } \cline { 5 - 6 } Group & $M$ & SEM & & $M$ & $S E M$ \\
\hline RS-1 & 96 & 1 & 346 & 7 \\
RS-2 & 102 & 2 & 325 & 8 \\
RS-3 & 106 & 3 & 345 & 6 \\
RS-4 & 95 & 1 & 341 & 9 \\
\hline
\end{tabular}

Note-Values are for Groups of 8-10 rats.

Table 4

Area Under Curve (AUC, in $\left.\mathrm{pg} \times \min \times 10^{3}\right)$ Measures of Plasma Norepinephrine (NE) and Epinephrine (EPI) for Rats on Experimental Day 28 During and After a 30-min Period of Restraint Stress (RS)

\begin{tabular}{crcccc}
\hline & \multicolumn{4}{c}{ AUC } \\
\cline { 2 - 6 } Treatment & \multicolumn{2}{c}{ NE } & & \multicolumn{2}{c}{ EPI } \\
\cline { 2 - 6 } Group & $M$ & SEM & & $M$ & SEM \\
\hline RS-1 & 22.5 & 2.7 & 27.4 & 2.4 \\
RS-2 & 13.0 & 1.2 & & 14.0 & 3.3 \\
RS-3 & 10.9 & 1.7 & 11.7 & 1.5 \\
RS-4 & 9.6 & 1.4 & 11.2 & 1.8 \\
\hline
\end{tabular}

Note-Values are for Groups of 5-8 rats.

$=3.01, p<.05$ ], with values for Groups RS-3 and RS4 significantly less than those for RS- 1 control animals ( $p$ s $<.05$; refer to Table 2 ).

Resting values of MAP and HR are summarized in Table 3. Values for MAP differed significantly across treatment groups $[F(3,32)=3.89, p<.05]$. MAPs for Group RS-3 were significantly greater than those of RS1 controls and RS-4 animals $(p<.05)$. Values for resting HR were similar across groups $(p>.1)$.

Baseline plasma levels of norepinephrine (Figure 1) and epinephrine (Figure 2) were similar for the rats of the four groups. When the rats in Group RS-1 were exposed to RS for the first time on Day 28, plasma levels of norepinephrine peaked at levels that were approximately 5fold greater than baseline at 5 and 15 min of RS. Plasma norepinephrine decreased by 30 min of RS to levels that were 3-fold greater than baseline, and returned to basal values by $15 \mathrm{~min}$ post-RS. Plasma epinephrine increased dramatically in rats exposed to RS for the first time and peaked at levels that were approximately 11 -fold greater than baseline at $15 \mathrm{~min}$ of RS. At the end of RS, plasma epinephrine had decreased to levels that were 5 -fold greater than baseline and remain elevated to $15 \mathrm{~min}$ post-RS.

Relative to the rats in the RS-1 group, the rats in the other three groups exhibited dramatic and statistically significant decreases in plasma levels of norepinephrine and epinephrine during the 30 min of RS on Day 28 . These attenuated plasma catecholamine responses of Groups RS$2, \mathrm{RS}-3$, and RS-4 were reflected in significant alterations in AUCs for norepineprhine $[F(3,22)=8.97, p<.001]$ and epinephrine $[F(3,22)=11.68, p<.001]$ (refer to Table 4). AUCs for both catecholamines were significantly greater in Group RS-1 relative to the other three groups (all $p \mathrm{~s}<.05$ ).

\section{DISCUSSION}

Our findings in this study indicate that laboratory rats habituate quite rapidly to daily bouts of RS. Compared to first-time stressed rats, the rats that were exposed to RS for the 6th, 13th, or 27th time exhibited significant

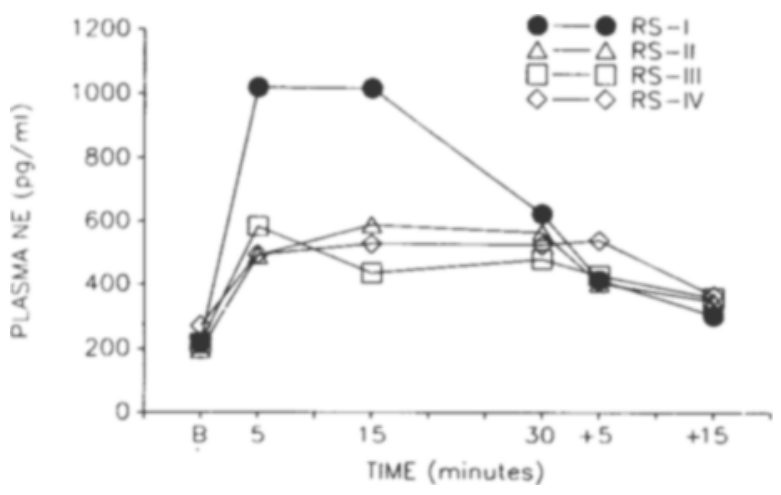

Figure 1. Plasma levels of norepinephrine (NE) in rats under baseline conditions (B) and during and after their 1st (RS-1), 6th (RS2), 13th (RS-3), or 27th (RS-4) session of restraint stress (RS). Values are the means for groups of 5-8 rats.

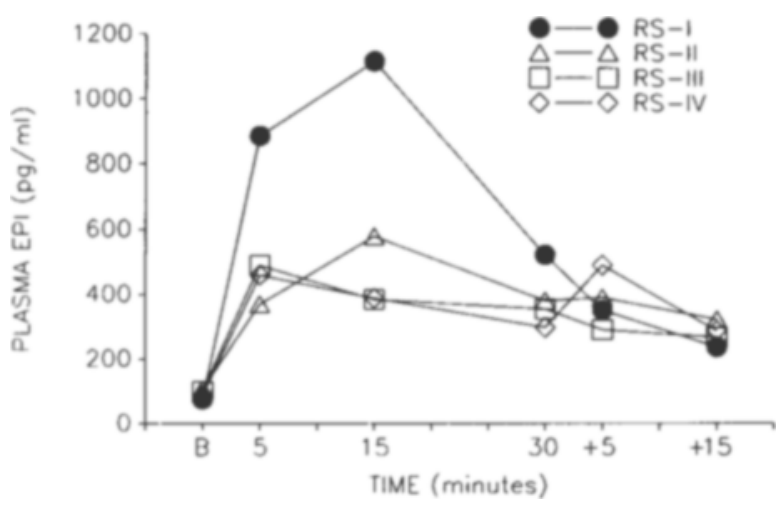

Figure 2. Plasma levels of epinephrine (EPI) in rats under baseline conditions (B) and during and after their 1st (RS-1), 6th (RS2), 13th (RS-3), or 27th (RS-4) session of restraint stress (RS). Values are the means for groups of 5-8 rats. 
attenuation of the RS-induced increases in plasma levels of both catecholamines. In addition, the animals in Groups RS-3 and RS-4 gained significantly less weight over the course of the experiment than did the handled controls. Reduced weight gain provides an additional indication of the stressful nature of the experimental protocol (Giralt, Garcia-Marquez, \& Armario, 1987).

There was a tendency for the rats in the RS-2 and RS-3 groups to have higher resting MAPs than those of the unstressed controls. However, this trend was not consistent, as the rats in the RS-4 group had resting MAPs that were similar to those of the controls. Previous studies from our laboratory have shown that resting blood pressure is unaffected by chronic intermittent stress (Konarska et al., 1989a). Although some researchers have suggested that chronic intermittent immobilization stress produces longlasting increases in systolic blood pressure in laboratory rats (Lamprecht, Williams, \& Kopin, 1973), we have not been able to replicate their findings.

These results are consistent with previous research from our laboratory (Konarska et al., 1989a) and the work of others (Adamicza, Tarnocky, \& Nagy, 1980; DeTurck \& Vogel, 1980; Kvetnansky et al., 1984; Ostman-Smith, 1979) regarding the reduced sympathetic-adrenal medullary responses of laboratory rats to chronic intermittent stress. Related studies have shown that other stressresponsive neuroendocrine systems, including the hypothalamic-pituitary-adrenocortical axis and lactotrophs of the anterior pituitary, become less responsive when test animals are exposed on a regular basis to the same stressful stimulus (Armario, Castellanos, \& Balasch, 1984; Armario, Lopez-Calderon, Jolin, \& Balasch, 1986; Dobracovova \& Jurcovicova, 1984; Pitman, Ottenweller, \& Natelson, 1988; Yelvington, Weiss, \& Ratner, 1985). Under such conditions, animals appear to mobilize physiological systems to the minimum extent necessary to maintain homostasis during stressful stimulation (McCarty et al., 1988; McCarty \& Stone, 1984).

One possible confounding variable in any study involving chronic intermittent stress relates to the effects of the stress protocol on the regulation of food intake and body weight. It is well established that chronic intermittent stress results in reductions in food intake and body weight in laboratory rats (Armario, Campmany, \& Hidalgo, 1986; Giralt \& Armario, 1989). Given that reductions in caloric intake might affect the sympathetic nervous system response to stress (Weick, Ritter, \& McCarty, 1983; Young \& Landsburg, 1977), it could be argued that the reduced sympathetic responses of chronically stressed animals result from the combined effects of habituation and reduced food intake.

In the present study, this issue was addressed indirectly in the RS-2 group. Although plasma catecholamine responses were reduced significantly in the rats of this group relative to RS-1 controls, body weights of the rats in the two groups were quite similar. In addition, plasma catecholamine responses in Group RS-2 were similar to those of Groups RS-3 and RS-4 in spite of significant reductions in body weights for the rats in the latter two groups.

If plasma catecholamine responses are reduced during chronic intermittent stress as an energy-conserving strategy, why then are the catecholamine biosynthetic and storage capacities of sympathetically innervated tissues and the adrenal medulla increased following even a single exposure to stress? It would appear that the energyrequiring processes of catecholamine synthesis and storage would cancel much of the gain from the energyconserving processes associated with reduced catecholamine release/secretion during subsequent exposures to the same stressor.

To address this apparent paradox, we took animals that were stressed by chronic daily exposure to one stressor (homotypic condition) and exposed them to a novel stressor (heterotypic condition). Our findings indicate that the plasma catecholamine responses of chronically stressed animals are exaggerated relative to controls exposed to an identical stressor for the first time (Konarska et al., $1989 \mathrm{~b})$. We have suggested that the heterotypic stressor actuallly presents a greater homeostatic challenge to previously stressed animals than to naive controls. Thus, the increased catecholamine synthetic and storage capacities of chronically stressed animals provide a buffer against exposure to a heterotypic stressor and permit a greater physiological response to the novel and unexpected stimulus (McCarty et al., 1988; McCarty \& Stone, 1984).

To date, many studies that have utilized a paradigm of chronic daily stress have included stress exposures over a 4-12-week period, with some studies running as long as 1 year (refer to McCarty, 1989). However, the present findings indicate that habituation to a homotypic stressor can occur quite rapidly, with the exact time course related to the intensity of the stressor. With relatively minor stressors such as restraint, habituation occurs in as few as six exposures. With more intense stressors such as immobilization, footshock, and cold exposure, habituation may require a greater number of daily exposures.

An issue that should be addressed in future studies is the relationship between habituation to a homotypic stressor and sensitization to a heterotypic stressor. If our hypothesis is correct as presented above, we would predict that sensitization of plasma catecholamine responses to a heterotypic stressor would be maximal when adrenal medullary catecholamine biosynthetic enzyme activities attain peak values. Ongoing studies in our laboratory are designed to address this hypothesis and to test further the validity of the dual-process theory of habituation (Groves \& Thompson, 1970) as it relates to physiological responses to chronic intermittent exposure to stressors.

\section{REFERENCES}

Adamicza, A., TARnocky, K., NAGY, S. (1980). Effects of previous bleeding on the response of plasma epinephrine and norepinephrine levels of conscious dogs in hemorrhagic shock. Circulatory Shock, 7, 251-259.

Armario, A., Campmany, L., \& Hidalgo, J. (1986). Metabolic ef- 
fects of chronic ACTH administration: Interaction with response to stress. Phamacology, 33, 235-240.

Armario, A., Castellanos, J. M., \& Balasch, J. (1984). Dissociation between corticosterone and growth hormone adaptation to chronic stress in the rat. Hormone \& Metabolic Research, 16, 142-145.

Armario, A., Lopez-Calderon, A., Jolin, T., \& Balasch, J. (1986). Response of anterior pituitary hormones to chronic stress: The specificity of adaptation. Neuroscience \& Biobehavioral Reviews, 10, 245-250.

Chiveh, C. C., \& Kopin, I. J. (1978). Hyperresponsivity of spontaneously hypertensive rats to indirect measurement of blood pressure. American Journal of Physiology, 234, H690-H695.

DAPRADA, M., \& ZURChER, G. (1976). Simultaneous radioenzymatic determination of plasma and tissue adrenaline, noradrenaline and dopamine within the femtomole range. Life Sciences, 19, 1161-1174.

DETURCK, K. H., \& VOGEL, W. H. (1980). Factors influencing plasma catecholamine levels in rats during immobilization. Pharmacology, Biochemistry \& Behavior, 13, 129-131.

Dobracovova, M., \& Jurcovicova, J. (1984). Corticosterone and prolactin responses to repeated handling and transfer of male rats. Experimental \& Clinical Endocrinology, 83, 21-27.

Giralt, M., \& Armario, A. (1989). Individual housing does not influence the adaptation of the pituitary-adrenal axis and other physiological variables to chronic stress in adult male rats. Physiology \& Behavior, 45, 477-481.

Giralt, M., Garcia-Marquez, C., \& Armario, A. (1987). Previous chronic ACTH administration does not protect against the effects of acute or chronic stress in male rats. Physiology \& Behavior, 40, 165-170.

Goldstein, D. S., McCarty, R., Polinsky, R. J., \& Kopin, I. J. (1983). Relationship between plasma norepinephrine and sympathetic neural activity. Hypertension, 5, 552-559.

Groves, P. M., \& ThOMPSON, R. F. (1970). Habituation: A dual-process theory. Psychological Reviews, 77, 419-450.

KIRK, R. E. (1982). Experimental design: Procedures for the behavioral sciences. Monterey, CA: Brooks/Cole.

Konarska, M., Stewart, R. E., \& McCarty, R. (1989a). Habituation of sympathetic-adrenal medullary responses following exposure to chronic intermittent stress. Physiology \& Behavior, 45, 255-261.

Konarska, M., Stewart, R. E., \& MCCarty, R. (1989b). Sensitization of sympathetic-adrenal medullary responses to a novel stressor in chronically stressed laboratory rats. Physiology \& Behavior, 46, 129-135

Kopin, I. J., Eisenhofer, G., \& Goldstein, D. (1988). Sympathoadrenal medullary system and stress. In G. P. Chrousos, D. L. Loriaux, \& P. W. Gold (Eds.), Mechanisms of physical and emotional stress: Advances in experimental medicine and biology (Vol. 245, pp. 11-23). New York: Plenum.

KVETNANSKY, R. (1973). Transsynaptic and humoral regulation of adrenal catecholamine biosynthesis in stress. In E. Usdin \& $\mathrm{S}$. $\mathrm{H}$. Snyder (Eds.), Frontiers in catecholamine research (pp. 223-229). New York: Pergamon.

KVETNANSKY, R. (1980). Recent progress in catecholamines under stress.
In E. Usdin, R. Kvetnansky, \& I. J. Kopin (Eds.), Catecholamines and stress: Recent advances (pp. 7-18). New York: Elsevier/NorthHolland.

Kvetnansky, R, Gerwitz, G. P., Weise, V. K., \& Kopin, I. J. (1971) Enhanced synthesis of adrenal dopamine-beta-hydroxylase induced by repeated immobilization in rats. Molecular Pharmacology, 7, 81-86.

Kvetnansky, R., Nemeth, S., Vigas, M., Oprsalova, Z., \& JuRcovicova, J. (1984). Plasma catecholamines in rats during adaptation to intermittent exposure to different stressors. In E. Usdin, R. Kvetnansky, \& J. Axelrod (Eds.), Stress: The role of catecholamines and other neurotransmitters (pp. 537-562). New York: Gordon \& Breach.

KVetNANSKY, R., Weise, V. K., \&oPin, I. J. (1970). Elevation of adrenal tyrosine hydroxylase and phenylethanolamine- $\mathrm{N}$-methyl transferase by repeated immobilization of rats. Endocrinology, 87, 744-749.

LAMPrecht, F., Williams, R. B., \& KoPIN, I. J. (1973). Serum dopamine-beta-hydroxylase during development of immobilizationinduced hypertension. Endocrinology, 92, 953-956.

MCCARTY, R. (1989). Stress research: Principles, problems and prospects. In G. R. Van Loon, R. Kvetnansky, R. McCarty, \& J. Axelrod (Eds.), Stress: Neurochemical and humoral mechanisms (Vol. 1 , pp. 3-13). New York: Gordon \& Breach.

MCCarty, R., HorwatT, K., \& KonarsKa, M. (1988). Chronic stress and sympathetic-adrenal medullary responsiveness. Social Science \& Medicine, 26, 333-341.

MCCARTY, R., Stone, E. A. (1984). Chronic stress and regulation of the sympathetic nervous system. In E. Usdin, R. Kvetnansky, \& J. Axelrod (Eds.), Stress: The role of catecholamines and other neurotransmitters (pp. 563-576). New York: Gordon \& Breach.

Ostman-SMith, I. (1979). Adaptive changes in the sympathetic nervous system and some effector organs of the rat following long term exposure or cold acclimation and the role of cardiac sympathetic nerves in the genesis of compensatory cardiac hypertrophy. Acta Physiologica Scandinavica, Suppl. 477, 1-119.

Peuler, J., \& Johnson, G. A. (1977). Simultaneous single isotope radioenzymatic assay of plasma norepinephrine, epinephrine and dopamine. Life Sciences, 21, 625-636.

Pitman, D. L., Ottenweller, J. E., \& Natelson, B. H. (1988). Plasma corticosterone levels during repeated presentation of two intensities of restraint stress: Chronic stress and habituation. Physiology \& Behavior, 43, 47-55.

WEICK, B. G., Ritter, S., \& MCCARTY, R. (1983). Plasma catecholamines in fasted and sucrose supplemented rats. Physiology \& Behavior, 30, 247-252.

Yelvington, D. B., Weiss, G. K., \& Ratner, A. (1985). Habituation of the prolactin response in rats to psychological stress. Psychoneuroendocrinology, 10, 95-102.

YouNG, J. B., \& LANDSBURG, L. (1977). Suppression of sympathetic nervous system during fasting. Science, 196, 1473-1475.

(Manuscript received August 18, 1989; revision accepted for publication November 3, 1989.) 